\title{
MARTIAL ARTS AND COMBAT SPORTS - SIMILARITIES AND DIFFERENCES IN TERMS OF THE BASIC ACTIVITIES OF A COACH
}

\author{
ZBIGNIEW BUJAK ${ }^{1}$, DARIUSZ GIERCZUK ${ }^{2}$, STEFAN LITWINIUK ${ }^{2}$ \\ The Josef Pilsudski University of Physical Education in Warsaw, \\ Faculty of Physical Education and Sport in Biała Podlaska, \\ Department of Combat Sports and Weightlifting ${ }^{1}$, Department of Sports Theory ${ }^{2}$ \\ Mailing address: Zbigniew Bujak, Faculty of Physical Education and Sport, \\ Department of Combat Sports and Weightlifting, 2 Akademicka Street, 21-500 Biała Podlaska, \\ tel.: +48 83 3428776, fax: +48 83 3428800, e-mail: bujakz@o2.pl
}

\begin{abstract}
Introduction. The aim of this study was to test the hypothesis that different approaches to the training process in the selfdefense and martial arts, reflected the hierarchical structure of the basic activities of a coach. Materials and methods. Opinions of 159 trainers with many years of experience in capoeira $(n=16)$, taekwon-do ITF version $(n=95)$ and wrestling $(\mathrm{n}=48)$ were collected. Diagnostic survey method was used, and the instrument was a questionnaire developed by Tumanian [7] and modified by Januszewski and Sterkowicz [8]. Results. Capoeira and wrestling trainers did not agree as to the status of any of the 20 coach's activities. The biggest differences were in assessing the significance of instructing trainees during competitions, developing planning process and first aid giving. Rsp ranks correlation coefficient $=0.66$, $\mathrm{p}<0.01$. Capoeira and taekwon-do coaches had consistent opinions in case of five activities. The largest differences occurred in terms of organizing and judging the competition and instructing trainees during competitions. Rsp rank correlation coefficient $=0.50, \mathrm{p}<0.05$. The opinions of taekwon-do and wrestling coaches were in line for two activities and the two activities were given different ranks. Rsp rank correlation coefficient $=0.71, \mathrm{p}<0.001$. Conclusions. Managing technical and physical preparation of trainees, as well as their training process and body control, were the most important activities of a coach in three combat variations. Scientific-methodical research was considered unimportant. None of the surveyed coaches agreed with others on the importance of professional activities, and their rank does not differentiate representatives of the three types of combat.
\end{abstract}

Key words: martial arts, combat sports, professional activities of a trainer

\section{Introduction}

In the area of combat skills, there is a lot of semantic and pragmatic confusion. The author of the theory of martial arts [1] organizes and defines some areas, proposing conceptual order based on praxeology. However, still in common use are different ways of perceiving, understanding and naming several aspects of the direct confrontation between human beings. Similarly to the area of sports science, where for many years Pertyński advocates for terminology unification [2].

The basis for the distinction between martial arts and martial sports is the goal of training, which determines many other activities, approaches and declarations. Not always and not in all respects Asian philosophy finds acceptance, understanding and willingness to adapt to different cultures. The more so, because the modern training process evolved, and in some areas undergone even revolutionary changes [3]. One of them is widespread approval of sports competition and redefined approach to training and the rejection or marginalization of ethical and moral grounds. This importance of sportsmanship seems to be the primary factor in confusion.

An example of this may be a non-Olympic taekwon-do. According to Choi Hong Hi, sports competition was only one element of a long training process [4]. Taking part in competitions requires versatility, as it covers up to 5 competitions substan- tially different in motor and technical terms. The advantage is that athletes with different motor, somatic or psychological abilities can participate. The drawback - the lack of mandatory participation in all competitions all around and the fact that only one of them (fighting sports) met the criteria belonging to the martial arts [1]. Currently, in taekwon-do from the initial training stage workouts are carried out in preparation for successful competing of children aged 10-11 years. Thus, despite the declaration of belonging to a group of martial arts, most trainers strictly implement sports and in competitions take part individuals without a predisposition to the sport, because enrollment does not apply any form of selection.

In capoeira, athletic competition doesn't take place, and attempts to develop a framework for competition proved to be wide the mark [5]. So this variation belongs exclusively to martial arts/self-defense, both at declarative and practical level.

A typical combat sport is wrestling, and the first mention about wrestling struggles dates back 4,000 years. Wrestling was always perceived as competitive or Olympic sport. Currently, sports competitions are conducted in 50 different varieties [6].

Regardless of the classifications and definitions, training goals or declarations about training profile, all the trainer's (instructor's) operations can be contained in 20 basic professional activities. Their importance in individual sports allows for identifying their specifics and building appropriate programs for 
training coaching staff and rationalize any follow-up knowledge and skills.

The aim of this study was to test the hypothesis that different approaches to the training process in the arts of self-defense and martial arts, reflected in the hierarchical structure of the basic activities of a coach.

\section{Material and methods}

Opinions of 159 trainers were collected, leading capoeira martial arts training $(\mathrm{n}=16)$, taekwon-do ITF version including both the martial arts and combat sports $(n=95)$ and combat sport with the longest Olympic status - wrestling ( $\mathrm{n}=48)$ (Tab. 1). Wrestling coaches were the oldest (mean age 36 years) and have worked for the longest time (over 8 years). However, taekwon-do trainers stood longest training experience (over 12 years).

Table 1. The characteristics of the respondents (mean \pm SD)

\begin{tabular}{|l|c|c|c|}
\hline \multicolumn{1}{|c|}{ Variable } & $\begin{array}{c}\text { Capoeira } \\
(\mathbf{n}=16)\end{array}$ & $\begin{array}{c}\text { Taekwon-do } \\
(\mathbf{n}=95)\end{array}$ & $\begin{array}{c}\text { Wrestling } \\
(\mathbf{n}=48)\end{array}$ \\
\hline Age (years) & $18.1 \pm 3.6$ & $27.1 \pm 7.1$ & $35.5 \pm 10.2$ \\
\hline Training experience (years) & $3.4 \pm 2.2$ & $12.2 \pm 5.4$ & $11.4 \pm 5.0$ \\
\hline Trainer experience (years) & $0.6 \pm 1.4$ & $5.1 \pm 6.2$ & $8.4 \pm 9.4$ \\
\hline
\end{tabular}

Utilizing the diagnostic survey, a questionnaire was used developed by Tumanian [7] and modified by Januszewski and Sterkowicz [8].

The questionnaire contained a list of 20 basic activities of a coach, the subjects were given the rank by key: 1 - very important, 2 - important, 3 - less important, 4 - unimportant. Activities of a coach include:

1. Supervising general fitness

2. Supervising tactical training

3. Supervising technical training

4. Supervising volitional condition of competitors

5. Supervising theoretical training of competitors

6. Instructing the students during the competition

7. Supervising the training process and the condition of the competitor's body

8. Supervising the progress of the students' school education

9. Organization of competitions and umpiring

10. Organization of sports camps

11. Organization of educational activities in a group

12. Organization of regeneration and leisure

13. Planning the competitors' preparation process

14. Improving the competitors' personal conduct

15. Scientific and methodology research

16. Preparing documentation and reporting

17. Recruitment and selection for training classes

18. Training of instructors and umpires

19. Problem solving in terms of training organization

20. First aid

For the results analysis some statistics were used, like mean, standard deviation, dispersion measures, the weighted average for each activity arranging them on a positioning scale, agreement of views was examined by calculating the Spearman rank correlation coefficient "rsp".

\section{Results}

According to respondents, the most important activities of a capoeira instructor, included physical preparation of a trainee (rank 1), technical preparation (rank 2) and giving the first aid (rank 3) (Fig.1).

In the opinion of the respondents the least important was the organization and judging competitions (rank 20), the preparation of instructors and judges (rank 19) and conducting scientific-methodical research (rank 18).

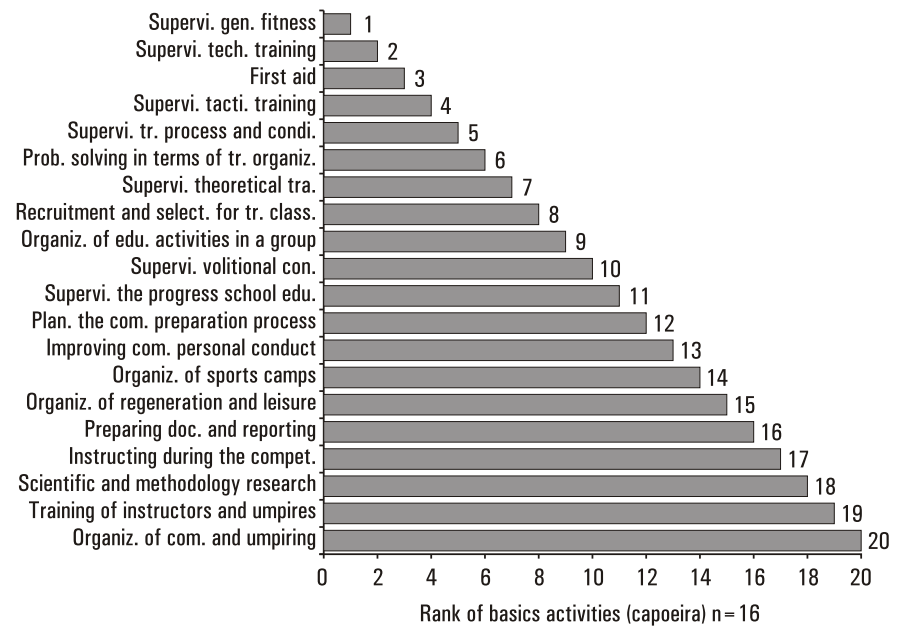

Figure 1. The hierarchy of activities of a coach in the opinions of trainers capoeira (an ordinal variable: rank activities)

Taekwon-do coaches as the most important in their work find managing technical preparation (rank 1), physical preparation (rank 2), and the planning process to prepare athletes (rank 3) (Fig. 2). As activities of little or no importance respondents considered scientific-methodical research (rank 20), monitoring the progress of trainees in school education (rank 19), and organization of sports camps (rank 18).

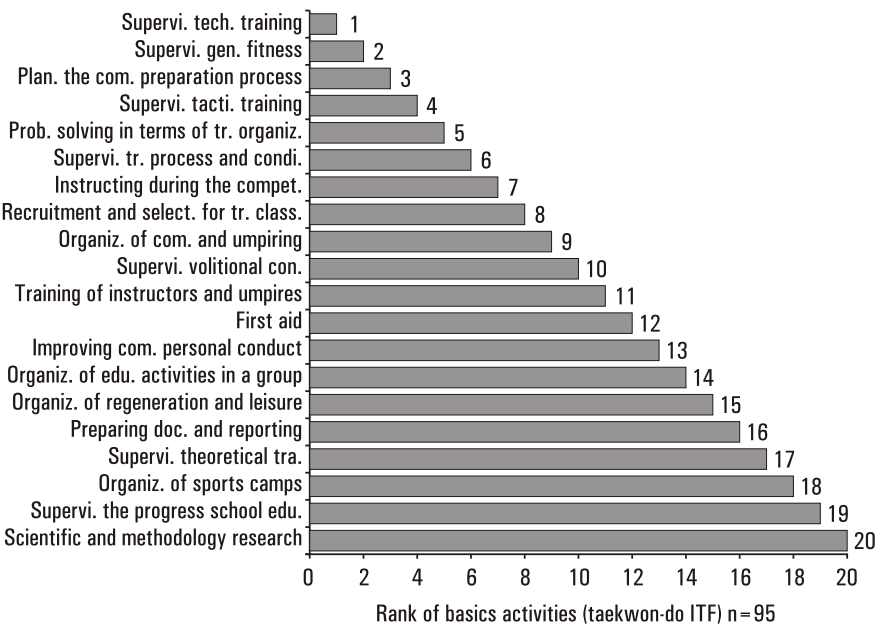

Figure 2. Activities rank of a taekwondo coach (an ordinal variable: the value of operations) 
Wrestling coaches as the most important in their work recognized directing technical preparation (rank 1), directing the tactical preparation (rank 2) and directing the physical preparation of a trainee (rank 3) (Fig. 3). The least important activities were documentation and reporting (rank 20), scientific-methodical research (rank 19) and the organization and judging competitions (rank 18).

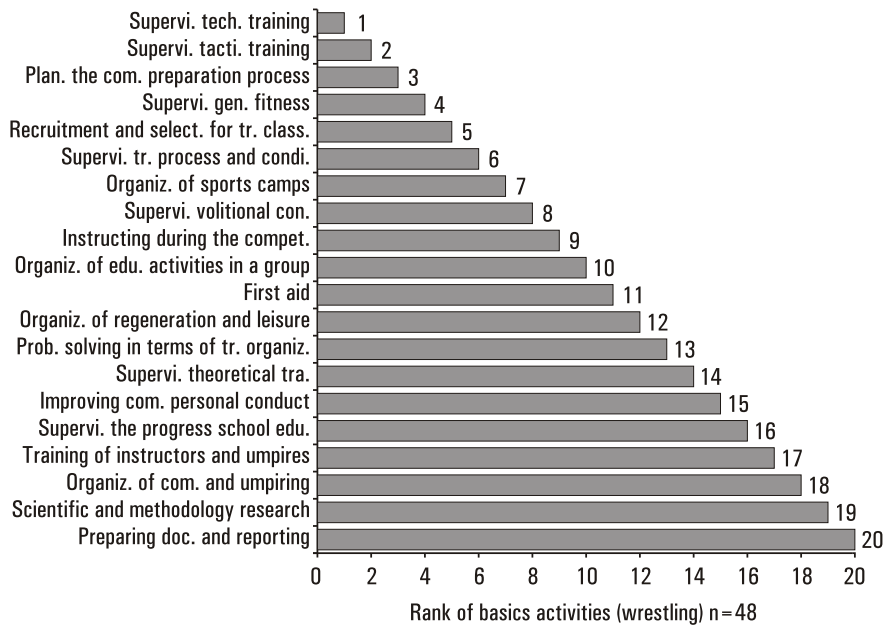

Figure 3. The structure of the importance of professional activities of wrestling trainer (an ordinal variable: rank activities)

Capoeira and wrestling trainers could not agree as to the status of any 20 basic activities of a coach (Fig. 4). The biggest differences were in assessing the significance of instructing trainees during competitions (rank 17 and 9), the planning process to prepare athletes (rank 12 and 4) and first aid (rank 3 and 11). However a similar opinions were expressed in relation to the role of directing the technical preparation of trainees (rank 2 and 1), controlling the training process and the state of the athlete's body (rank 5 and 6), the organization of educational work in the group (rank 9, and 10), as well as scientific-methodological research (rank 18 and 19). Rank correlation coefficient was high $(\mathrm{rsp}=0.66, \mathrm{p}<.01)$.

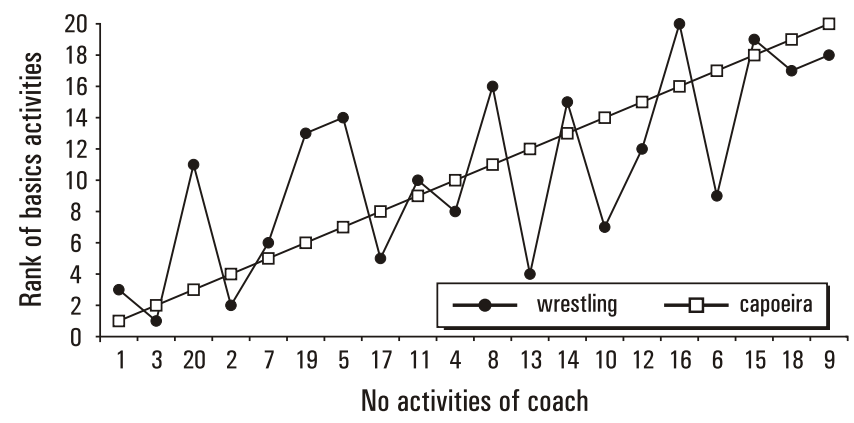

Figure 4. Comparison ranks assigned to activities by professional wrestling and capoeira trainers (an ordinal variable: decreasing importance of capoeira instructors' professional activities)

In capoeira and taekwon-do trainers a consensus occurred in case of 5 activities. These were: management of tactical preparation (rank 4) and directing volitional preparation of trainees (rank 10), conducting recruitment to training groups and selection (rank 8), raising the personal culture of athletes (rank 13) and the organization of the renewal and recreation process (rank 15).

The biggest differences in terms professional activities have occurred in the organization and judging competitions (rank 20 and 9), instructing trainees during competitions (rank 17 and 7) and the planning process to prepare athletes (rank 12 and 3). Correlation between opinions of capoeira and taekwon-do trainers was moderate $(\mathrm{rsp}=0.50, \mathrm{p}<.05)$.

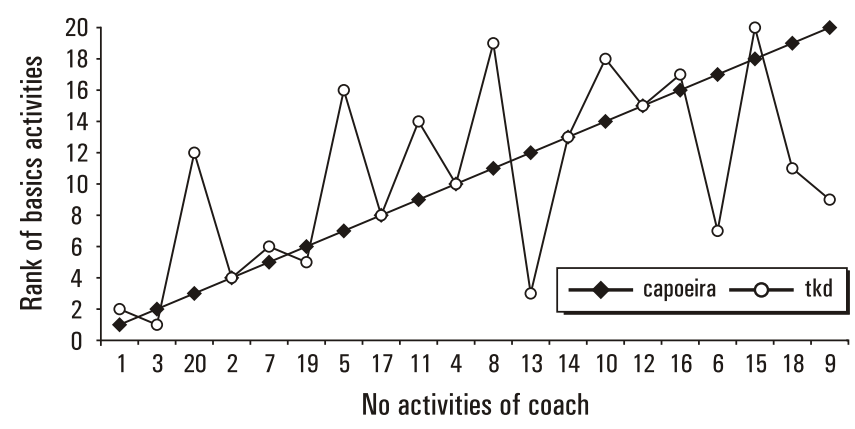

Figure 5. Comparison of the importance of professional activities in capoeira and taekwon-do (an ordinal variable: decreasing importance of capoeira instructors' professional activities)

Comparing opinions on the importance of professional activities of wrestling and taekwon-do coach, two of them were assigned identical rank: directing the technical preparation of a trainee (rank 1) and control of the training process and the state the athlete's body (rank 6) (Fig. 6). The biggest differences were related to organizing sports camps (rank 18 and 7) and solving organizational problems (rank 9, and 18). The correlation between ranks of professional activities in the training process in both combat variations proved to be significant $(\mathrm{rsp}=0.71, \mathrm{p}<0.001)$.

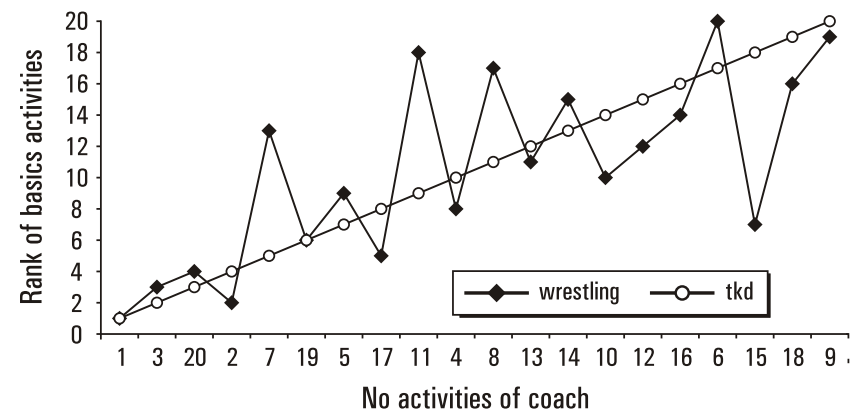

Figure 6. Comparison of the importance of professional activities in taekwon-do and wrestling (an ordinal variable: decreasing importance of taekwondo trainers' professional activities)

Capoeira trainers differed the most in case of the importance in their work of the supervision of the progress of their trainees in school education ( $\mathrm{cv}=46 \%$ ). Taekwon-do coaches expressed their extreme opinions (from very important to unimportant) in the role of directing the tactical and technical preparation of the competitor and first aid ( $\mathrm{cv}=45 \%)$. Among the wrestling trainers, the largest diversity of opinion on the importance of basic professional activities related to the managing the technical preparation of a trainee $(\mathrm{cv}=50 \%)$ 


\section{Discussion}

Capoeira trainers, despite the short period of employment (about 1 year) showed the logic in the evaluation of their most important activities. Both physical fitness and motor skills were considered the most important in the preparation of capoeiristas. Complex in terms of coordination evolutions performed to the music, may be the cause of musculoskeletal injuries, hence the high rank skills for providing emergency assistance. However, activities pertaining to competition in sports (organization, preparation, seconding in the fight) were evaluated as unimportant in case of a typical martial arts, which is capoeira. Extreme opinions on the evaluation of school education of practitioners probably appeared due to different perceptions of a trainer's role in martial arts. According to tradition, trainers didn't limit their activities only to training. They raised, shaped beliefs, cared about education, they were role models to follow in all aspects $[9,10]$. Currently, in many cases, these roles are reduced to instruct in the gym.

Taekwon-do coaches, who place their discipline among martial arts that accept sports rivalry, as the most important activities cited those directly related to the technology of sports training (technical and physical training process planning, control of training and adaptation processes, a variety of activities during competitions). Similar results were obtained by Sterkowicz [11] while studying judo trainees and ju-jitsu and karate instructors [12]. Opinions of surveyed taekwon-do trainers $(\mathrm{n}=95)$ were similar to the views of II-III dan holders, but differed from the trainers at level IV-VII dan [13]. Low place in the ranking of theoretical preparation management of trainees (rank 16), suggests marginalization of knowledge of taekwon-do in the training process, as in case of judo and brazilian ju-jitsu $[11,14]$, despite the great importance it should play, according to Choi, in teaching Korean martial arts [4].

For wrestling coaches the most important activities were those, which allow effectively prepare for sports rivalry. Similar opinions were expressed by another group of wrestlers tested [15]. Concerns arise the fact of assuming as unimportant in the job of Olympic sport trainer (rank 20), record-keeping and reporting. Pre-planned work and its analysis should form basis for the next steps in the algorithm of effective and efficient training. [16] It is significant that for over 10 years the views of trainers on importance of documenting and settling their actions have not changed.

It turned out that opinions about the role of the professional activities of taekwon-do and wrestling trainers were significantly consistent ( $\mathrm{rsp}=71$ ). Thus, similar actions in taekwondo and wrestling training determine the training procedure and decide on the competitive effectiveness, despite the radically different means of affecting the rival and different motor skills profiles.

The hypothesis that professional activities differentiate trainers in various martial arts should be partially verified positive and partly falsified. The differences between the weighted average in basic activities of a coach in the martial arts, Olympic sports and martial arts with sports aspirations, proved to be statistically insignificant, indicating identical or very similar meaning of eight activities in three variations of martial arts. On the basis of views on the importance of individual professional activities, it can be seen that taekwondo trainers are more inclined towards sports than martial arts.

\section{Conclusions}

1. The hierarchical structure of basic professional activities of a coach cannot uniquely identify a martial art or sport.

2. Managing the technical and physical preparation of a trainee as well as training process and body control belonged to very important professional activities of a coach in three martial sports variations.

3. Scientific-methodical research was considered unimportant in the capoeira, taekwon-do and wrestling training process.

4. The importance of professional activities of a taekwon-do coach places this variation closer to the sport than martial arts.

5. None of the responding trainers had identical views on the importance of basic professional activities.

6 . The content of the programs to prepare trainers in martial arts and sports should reflect the specific needs arising from the importance of the basic activities a coach.

\section{Literature}

1. Kalina R.M. (2000). Martial sports theory. Warszawa: COS. [in Polish]

2. Pertyński W. (2006). Barbarian in the palace of science. Leszno: PWSZ. [in Polish]

3. Harasymowicz J. (2007). Competences of combat sports and martial arts educators in light of the holistic fair self-defence model of training. Archives of Budo, 3 (7), 7-14.

4. Choi H.H. (1965). Taekwon-do: the art of self-defence. South Korea: Daeha.

5. Capoeira N. (2002). Capoeira. Roots of the dance-fight-game. Berkeley, USA: Blue Snake Books.

6. Chapman M. (2005). Wrestling tough. Dominate mentally on the mat. Champaign: Human Kinetics.

7. Tumanian G.S. (1985). A new complex subjects for physical culture departments - specialist sports coaches. Tieorija i Praktyka Fiziczeskoj Kultury, 12. [in Russian]

8. Januszewski J., Sterkowicz S. (1992). The importance of professional activities, as the basis for analysis of coach training programs (based on karate and archery). Rocznik Naukowy 25, 189-194. Kraków: AWF. [in Polish]

9. Ratti, O., Westbrook A. (1973). Secrets of the Samurai. Boston, USA: Charls E. Tuttle Co., Inc.

10. Vertonghen J., Theeboom M., Cloes M. (2012). Teaching in martial arts: the analysis and identification of teaching approaches in youth martial arts practice. Archives of Budo, 8 (4), 191-202.

11. Sterkowicz S. (1999). Professional activities of a judo coach. In S. Sterkowicz (Ed.), Professional activities of a martial sports coach (pp. 5-8). Kraków: AWF. [in Polish]

12. Sterkowicz S. (1998). Ju-jitsu. Selected aspects the art of selfdefense. Kraków: AWF. [in Polish]

13. Bujak Z., Litwiniuk S., Selwa Ch. (2012). Basic steps in the opinions of professional coach trainers Polish taekwon-do level II - VII Dan. Totally TaekwonDo 38, 83-90.

14. Bujak Z. (2012). Taekwon-do black belt. Theory, reality, practise. Biała Podlaska: MKS Żak. [in Polish]

15. Sterkowicz S., Biskup L., Ambroży T. (2001). Professional activities of wrestling and gimnastic coaches. In S. Sterkowicz (Ed.), Professional activities and research problems in the martial arts (pp. 7-16). ). Zeszyty Naukowe 38. Kraków: AWF. [in Polish]

16. Bompa, T.O., Haff G.G. (2009). Periodyzation. Theory and methodology of training. Champaign: Human Kinetics.

Submitted:December 10, 2012

Accepted: January 9, 2013 